\title{
Field testing of permeation grouting using microfine \\ cement
}

\section{Kazuyoshi Hashimoto ME}

Project engineer, Chuo Kaihatsu Corporation, Tokyo, Japan; Graduate student, Department of Civil Engineering, Tokyo University of Science, Chiba, Japan

2 Satoshi Nishihara BAgr

Chairman of Tokyo Branch, Chuo Kaihatsu Corporation, Tokyo, Japan

3 Shusuke Oji PhD

Project engineer, Chuo Kaihatsu Corporation, Tokyo, Japan

4 Tomohiro Kanazawa PhD

Project engineer, Nippon Steel \& Sumikin Cement Co., Ltd., Muroran, Japan
5 Shunsaku Nishie PhD

Chairman of Technology Centre, Chuo Kaihatsu Corporation, Tokyo, Japan

6 Ichiro Seko $\mathrm{PhD}$

President, Chuo Kaihatsu Corporation, Tokyo, Japan

7 Taichi Hyodo PhD

Assistant Professor, Department of Civil Engineering, Tokyo University of Science, Chiba, Japan

8 Yoshimichi Tsukamoto PhD

Professor, Department of Civil Engineering, Tokyo University of Science, Chiba, Japan
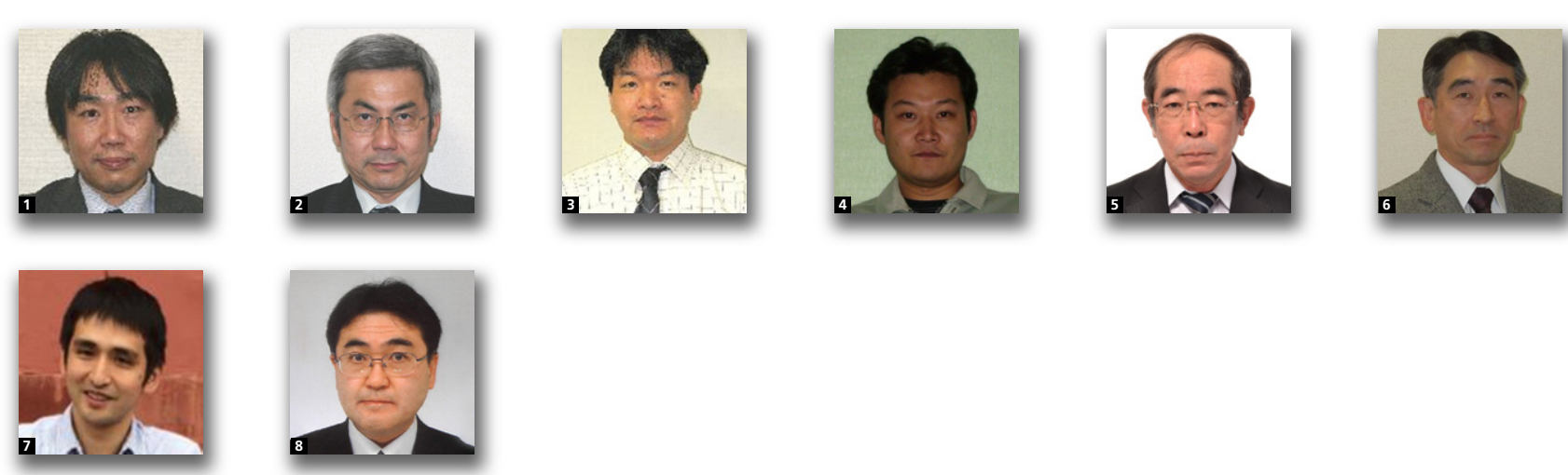

Field tests are conducted on permeation grouting of ultra-microfine cement to examine whether zones of improved soil of a sufficient size can be created economically in sand deposits, which would be expected to contribute to improving ground conditions as a countermeasure against soil liquefaction. Four different tests are carried out under different grouting conditions, where grouting is conducted with and without forcible injection pressures, using cement solutions of different concentrations of $(w / c)_{c s}=8$ and 12 . After two and a half months, the testing site is excavated and the surface appearances of improved soil are confirmed. The study proves that columns of improved soil of diameter 1.5-2 $\mathrm{m}$ and height of about $2.5 \mathrm{~m}$ can be built up in sand deposits of depth $3 \mathrm{~m}$. Some discussions are given on the filling ratio $\alpha$ and the ratio of mass of water to cement particles $(w / c)_{\text {is }}$ of the overall improved soil, leading to the presumption that, as far as relatively clean sand deposits are concerned, the radius of a column of improved soil can be estimated solely from the volume of cement solutions injected into sand deposits.

$\begin{array}{ll}\text { Notation } & \\ D_{\mathrm{r}} & \text { relative density } \\ D_{50} & \text { mean particle diameter } \\ e_{\mathrm{max}} & \text { maximum void ratio } \\ e_{\mathrm{min}} & \text { minimum void ratio } \\ F_{\mathrm{c}} & \text { fines content }<0 \cdot 075 \mathrm{~mm} \text { in particle diameter } \\ N_{\mathrm{sw}}^{\prime}, N_{\mathrm{sw} 1}^{\prime} & \text { converted values of } N_{\mathrm{sw}} \text { and } W_{\mathrm{sw}} \text { defined in } \\ & \text { Equation } 2 \\ N_{\mathrm{sw}} & \text { distribution of penetration resistance of SWS } \\ & \text { tests (half turns } / \mathrm{m}) \\ n & \text { porosity of soil }\end{array}$

$Q$

$R_{1}$

$V$

$V_{\mathrm{w}}^{\prime}$ and $V_{\mathrm{c}}$

$\left(M_{\mathrm{w}}^{\prime}\right.$ and $\left.M_{\mathrm{c}}\right)$

$V_{\mathrm{w}}$ and $V_{\mathrm{c}}$

$\left(M_{\mathrm{w}}\right.$ and $\left.M_{\mathrm{c}}\right)$

$W_{\mathrm{sw}}$ volume of cement solutions infiltrated liquefaction resistance of soil volume of improved soil column volumes (masses) of water and cement particles in the cement solutions which are permeated into the improved soil volumes (masses) of water and cement particles existing immediately after the injection of cement solutions within a volume of soil for improvement dead weight $(\mathrm{kN})$ 


$\begin{array}{ll}(w / c)_{\mathrm{cs}} & \begin{array}{l}\text { ratio of mass of water to cement particles of } \\ \text { cement solutions } \\ (w / c)_{\mathrm{is}}\end{array} \\ \begin{array}{l}\text { ratio of mass of water to cement particles of } \\ \text { overall improved soil } \\ \text { possible maximum value of the ratio of mass } \\ \text { of water to cement particles to induce solidifi- }\end{array} \\ \begin{array}{l}\text { cation of soil } \\ \text { filling ratio }\end{array} \\ \rho_{\mathrm{c}} & \text { density of cement particles } \\ \rho_{\mathrm{s}} & \text { density of soil particles } \\ \rho_{\mathrm{w}} & \text { density of water } \\ \sigma_{\mathrm{v}}^{\prime} & \text { effective overburden stress }(\mathrm{kPa})\end{array}$

\section{Introduction}

Soil liquefaction has been imposing some of the most disastrous effects on civil engineering infrastructures during recent earthquakes. It has also been during the recent earthquakes, especially in New Zealand and Japan, that a significant number of private housing estates have suffered from irrecoverable damage, mostly due to post-liquefaction settlement and tilt. One of the primary concerns among local geotechnical engineers and researchers has therefore become how to mitigate effects of soil liquefaction on small-scale existing structures built on liquefiable soil deposits. The lowering of the groundwater table and the construction of lattice-shaped improved soil walls by means of jet grouting are thought to provide most plausible solutions according to geotechnical engineers and researchers in Japan, provided a sufficient number of owners of private houses together agree to implement the changes. In looking at some of the recent research efforts, the effects of deep mixing configurations on the seismic response of an improved site have been an important issue when considering the relevance of using ground improvement technology for soil liquefaction mitigations (Mitrani and Madabhushi, 2010; Siddharthan and Porbaha, 2008a, 2008b; and others). Permeation grouting using sodium silicate solutions has also been widely applied for its mitigation effects on individual structures (e.g. Granata et al., 2015; Lirer et al., 2006; Tsukamoto et al., 2006, 2007), while the use of microfine cement for grouting has also been developed and examined (Markou and Droudakis, 2013; Tunçdemir and Ergun, 2009; and others). However, with the recent advent of ultra-microfine cement, with particle diameters on the order of $1 \mu \mathrm{m}$ (Kanazawa, 2012), it has become important to seek advancement in geo-technology for permeation grouting using such micro-scaled cement materials (Hashimoto et al., 2015). The advantage of using cement solutions for grouting instead of sodium silicate solutions lies in the fact that it may be possible to produce more lasting and resilient improved soil structures with higher strength and stiffness.

In this study, a series of field tests was carried out to examine whether permeation grouting of ultra-microfine cement would work on native soil deposits, and also to discover whether it could produce improved soil columns of suitable size for local countermeasures against soil liquefaction.

\section{Site conditions}

The field tests were conducted at a site located within the area of an industrial complex in Karatsu city of Saga in the Kyushu Island of Japan, as shown in Figure 1. The site is situated along the estuary of a local river, and its soil profile is shown in Figure 2, along with the $N$-values of standard penetration tests (SPTs) and the value of fines content $F_{\mathrm{c}}<0.075 \mathrm{~mm}$ in particle diameter. A layer of recent fill of sand and gravel mixtures covers the area of the test site down to a depth of $2 \mathrm{~m}$, and the groundwater level is found at a depth of $1.5 \mathrm{~m}$. A layer of a natural sand deposit is then found from a depth of 2-4 $\mathrm{m}$, which is underlain by a layer of silty sand. The values of fines content $F_{\mathrm{c}}$ of this natural sand deposit are as low as $5 \%$ or less, and the SPT $N$-values are also as low as 5. This natural sand deposit is therefore most likely to be susceptible to soil liquefaction in the event of any significant earthquakes. In a series of field tests carried out in this study, the aim was to build up circular columns of improved soil within this natural sand deposit by means of permeation grouting of ultra-microfine cement.

\section{Field testing}

The distance that a cement solution will permeate through voids of a saturated soil deposit may effectively determine the radius of a column of improved soil, thus it is worth exploring whether there may be any competent procedure to help accelerate permeation of cement solutions through saturated soil deposits. In a series of field tests carried out in this study, at a location close to some of the other boreholes used for injection of cement solutions, a borehole was set up, from which groundwater was pumped up and a flow of groundwater was induced around its periphery. Figure 3 shows a layout of the field tests. In total, four tests were performed using four different boreholes (numbers 1-4), at which cement solutions were introduced. These boreholes are herein called 'injection boreholes'. At these injection boreholes, polyvinyl pipes of $5 \mathrm{~cm}$ in diameter were penetrated down to a depth of $5 \mathrm{~m}$. Along these pipes, a series of long slits (narrow openings) were provided at the portions facing the sand deposit located at a depth of 2-5 $\mathrm{m}$ from the ground surface. These long slits allowed cement solutions to penetrate into the nearby sand deposit. Located at the centre of the injection boreholes numbers 1-3 was a borehole for pumping up groundwater, which is herein called the 'pumping up borehole'. Injection boreholes numbers 1-3 were thought to be under the influence of this pumping up borehole, whereas the injection borehole number 4 was thought to be less affected by the presence of this pumping up borehole. The testing assembly built up at the test site is shown in Figure 4.

Prior to conducting the field tests of permeation grouting, a series of Swedish weight sounding (SWS) tests was carried out 

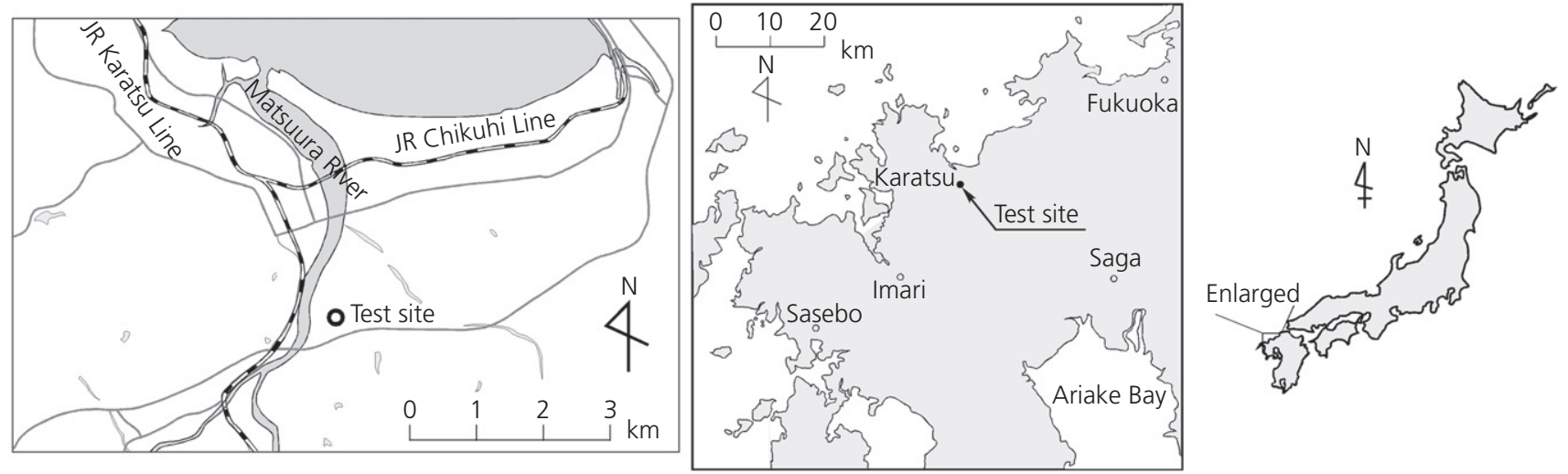

Figure 1. Location of a field testing site

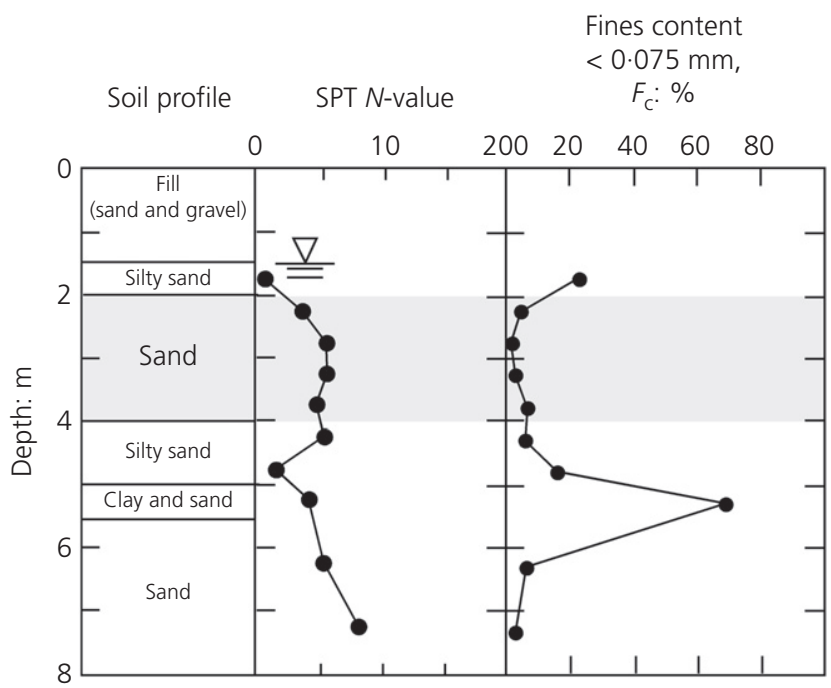

Figure 2. Soil profile of a field testing site

at the location close to each injection borehole. The details of the testing procedure and interpretation of test results are described by Tsukamoto et al. (2004). Figure 5 shows the distribution of penetration resistance denoted as $N_{\mathrm{sw}}$ with depth, which is observed at the location of Sws-1 close to the injection borehole of number 1. In SWS tests, a dead weight is mounted on the sounding equipment in the first phase of static penetration, which is denoted as $W_{\text {sw }}(\mathrm{kN})$ and takes values of $0 \cdot 15,0 \cdot 25,0 \cdot 5,0 \cdot 75$ and 1 . In the second phase of rotational penetration, resuming with a dead weight of $W_{\mathrm{sw}}=1(\mathrm{kN})$ mounted on, the parameter $N_{\mathrm{sw}}$ (half turns $/ \mathrm{m}$ ) represents the number of half turns of a handle per metre. The values of $W_{\mathrm{sw}}$ and $N_{\text {sw }}$ can then be converted to the values of relative density $D_{\mathrm{r}}$ as follows, as proposed by Tsukamoto et al. (2004)

1. $D_{\mathrm{r}}=\sqrt{\frac{\left(N_{\mathrm{sw}}+40 \times W_{\mathrm{sw}}\right)\left(e_{\mathrm{max}}-e_{\mathrm{min}}\right)^{2 \cdot 2}}{90} \sqrt{\frac{98}{\boldsymbol{\sigma}^{\prime}{ }_{\mathrm{v}}}}}$
2. $N_{\mathrm{sw}}^{\prime}=N_{\mathrm{sw}}+40 \times W_{\mathrm{sw}}, \quad N_{\mathrm{sw} 1}^{\prime}=N_{\mathrm{sw}}^{\prime} \sqrt{\frac{98}{\sigma_{\mathrm{v}}^{\prime}}}$

where $e_{\max }-e_{\text {min }}$ is a void ratio range and $\sigma_{\mathrm{v}}^{\prime}(\mathrm{kPa})$ is an effective overburden stress. Herein, the values of maximum void ratio $e_{\max }$ and minimum void ratio $e_{\min }$ are determined by the testing method stipulated by JGS (2000). The testing method stipulated by JGS (2000) uses a rigid mould of $6 \mathrm{~cm}$ inner diameter and $4 \mathrm{~cm}$ high, and is briefly described as follows. The value of $e_{\max }$ is obtained by loosely pouring a sand sample into this mould using a paper funnel, while the value of $e_{\min }$ is obtained by making a sand sample poured into this mould as dense as possible by hitting the side of the mould using a wooden hammer. With reference to the available soil samples of the sand deposit, a series of laboratory tests yielded the values of soil particle density $\rho_{\mathrm{s}}=2.66 \mathrm{~g} / \mathrm{cm}^{3}, e_{\max }=1.12$ and $e_{\min }=0.67$. It should also be noted here that the phase of static penetration yields $N_{\mathrm{sw}}^{\prime}=40 \times W_{\mathrm{sw}}$, since $N_{\mathrm{sw}}=0$. However, the phase of rotational penetration yields $N_{\mathrm{sw}}^{\prime}=N_{\mathrm{sw}}+40$, since $W_{\mathrm{sw}}=1$. The liquefaction resistance $R_{\mathrm{l}}$ can also be estimated from the values of $W_{\mathrm{sw}}$ and $N_{\mathrm{sw}}$ as follows, as proposed by Tsukamoto et al. (2015)

3. $R_{\mathrm{l}}=0 \cdot 016 \sqrt{N_{\mathrm{sw} 1}^{\prime}} \quad$ (for clean sand)

4. $\quad R_{\mathrm{l}}=0.02 \sqrt{N_{\mathrm{sw} 1}^{\prime}} \quad$ (for sand with silt and silty sand)

where Equation 3 is used to estimate $R_{1}$ of the sand deposit at the field test site. The values of relative density $D_{\mathrm{r}}$ and liquefaction resistance $R_{1}$ thus estimated are also plotted against depth, as shown in Figure 5. The values of the penetration resistance $W_{\mathrm{sw}}$ and $N_{\mathrm{sw}}$ observed at Sws-4 and the values of relative density $D_{\mathrm{r}}$ and liquefaction resistance $R_{1}$ estimated in the same manner as described above are also plotted against depth in Figure 6. The relative density $D_{\mathrm{r}}$ of the sand deposit 
Ground Improvement Volume 169 Issue GI2
Field testing of permeation grouting

using microfine cement

Hashimoto, Nishihara, Oji et al.

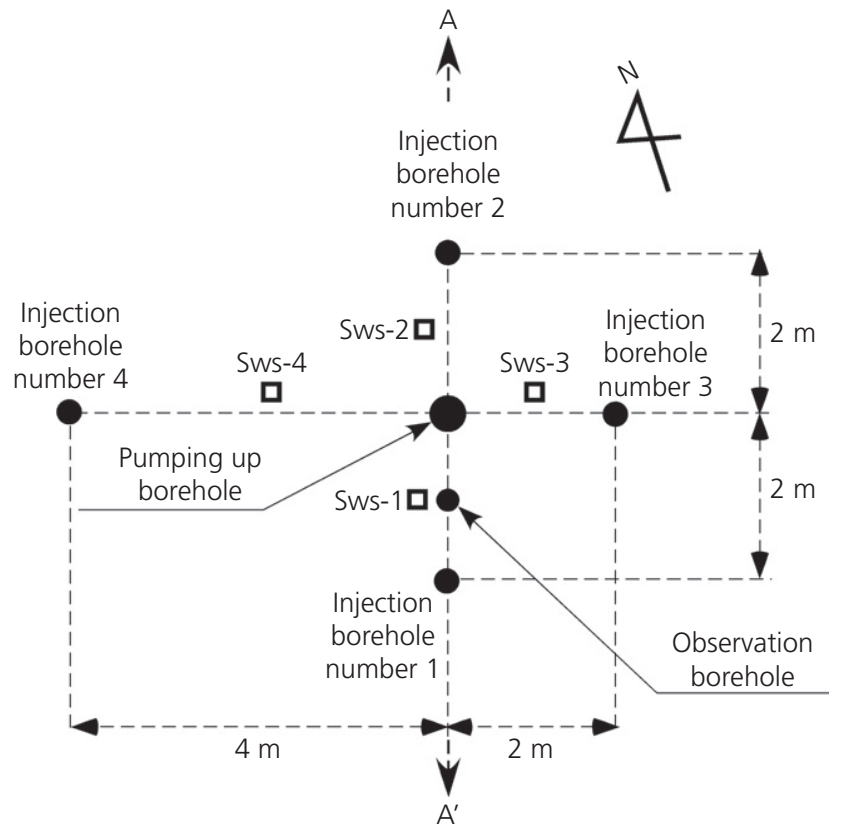

(a)

Figure 3. Layout of a field testing site: (a) plan view of a test site and (b) cross-section at $A-A^{\prime}$

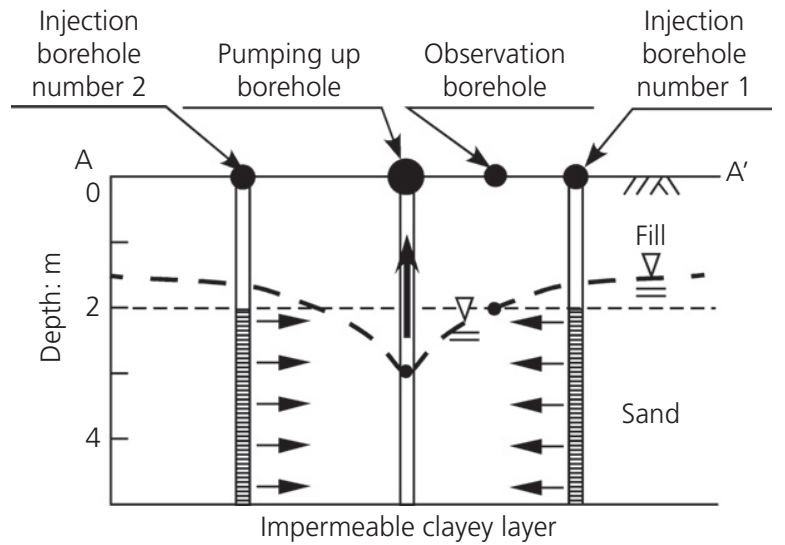

(b)
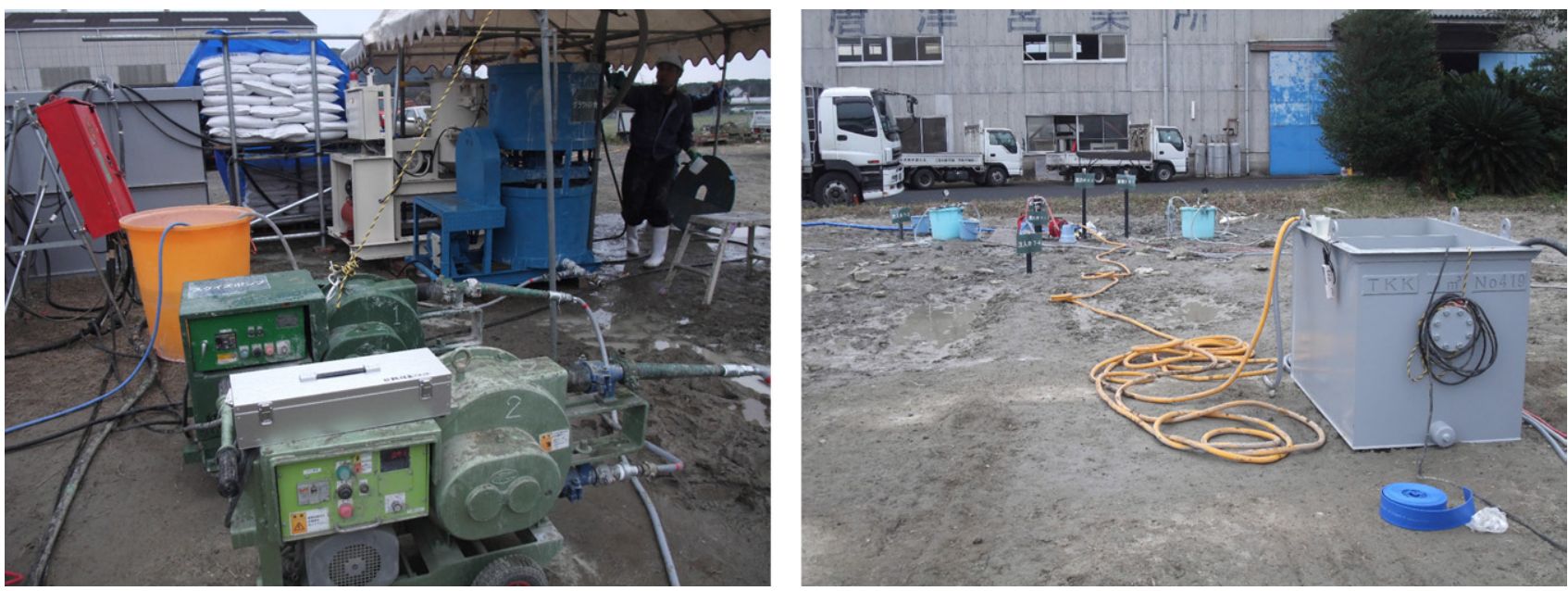

Figure 4. Testing assembly at the test site

is found as low as about $40-50 \%$, thus yielding a liquefaction resistance $R_{1}$ as low as $0 \cdot 15-0 \cdot 2$.

In total, four field tests were conducted in two successive days. During the 2 days of field tests, the groundwater level at the pumping up borehole was lowered down to $1.5 \mathrm{~m}$ below the original groundwater level. On the first day, 10 December 2014, two field tests were carried out at the injection boreholes numbers 1 and 2. Cement solutions of $(w / c)_{\mathrm{cs}}=12$ were prepared with some appropriate dispersing agents, and were injected into these two injection boreholes simultaneously, keeping the rates of injection at $20 \mathrm{l} / \mathrm{min}$ initially with some appropriate injection pressures. However, about 1 hour after the injection started, it became difficult to maintain the rates of injection, and they were gradually reduced to prevent the cement solutions from overflowing from the top of the injection boreholes located $1 \mathrm{~m}$ above the ground surface. Overall, in total 21931 of cement solutions were percolated into the 

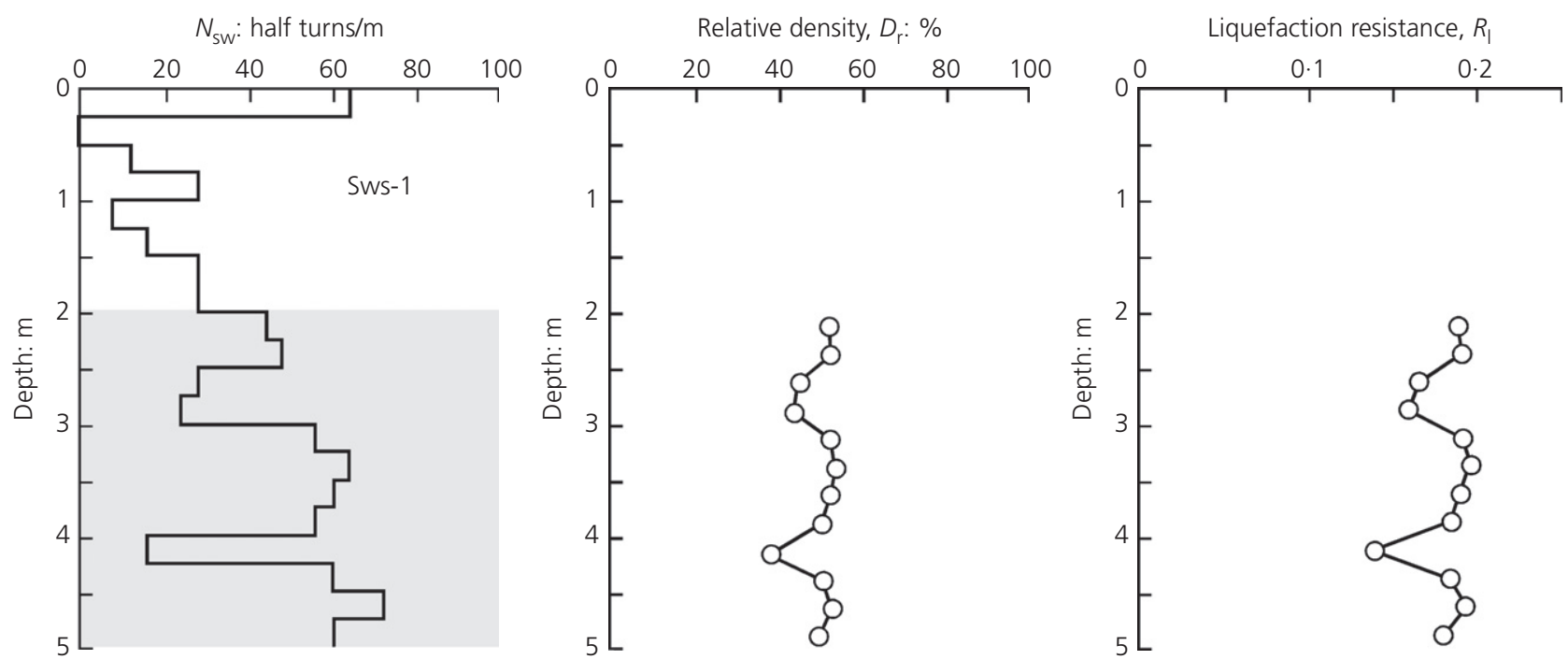

Figure 5. Results of SWS test and estimated distributions of relative density $D_{\mathrm{r}}$ and liquefaction resistance $R_{\mathrm{l}}$ with depth at Sws-1
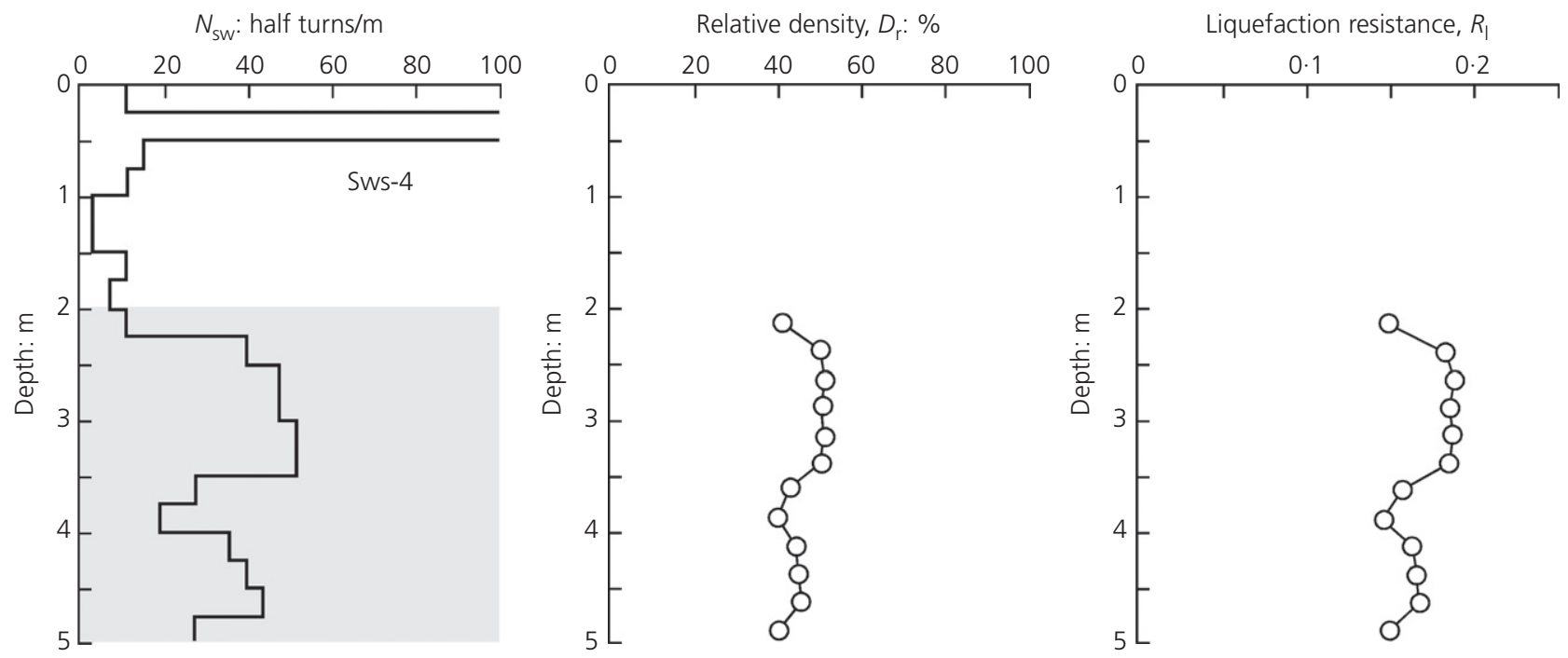

Figure 6. Results of SWS test and estimated distributions of relative density $D_{\mathrm{r}}$ and liquefaction resistance $R_{\mathrm{l}}$ with depth at Sws-4

injection borehole number 1 , and 5221 of cement solutions at injection borehole number 2 .

On the second day, 11 December 2014, the other two field tests were carried out using injection boreholes numbers 3 and 4. Cement solutions of $(w / c)_{\mathrm{cs}}=8$ were prepared with some appropriate dispersing agents, and were injected into these two injection boreholes simultaneously. From the experiences gained on the first day, the injection of the cement solutions was carried out without any forcible injection pressures. The rates of injection were initially 12 and $25 \mathrm{l} / \mathrm{min}$ at injection boreholes numbers 3 and 4 . However, they gradually reduced down to 2 and $6.5 \mathrm{l} / \mathrm{min}$ about two and a half hours later. Overall, in total 9601 of cement solutions were percolated into the injection borehole number 3, and 27651 of cement solutions into injection borehole number 4. Regarding the effects of pumping up groundwater, there appear to be no clear indications of the facilitation of 
cement solutions' infiltration as far as the present study is concerned.

\section{Confirmation of formation of improved soil columns}

After curing periods of about two and a half months, some excavations were carried out around the locations of improved soil on 26 and 27 February 2015. Figure 7 shows the top portions of improved soil formed at the injection boreholes numbers 1 and 4, and Figure 8 shows the close-up view at number 4 . The top surfaces of improved soil are found at depths of $2 \cdot 4-2 \cdot 7 \mathrm{~m}$ below the original ground surface. It is evident in Figures 7 and 8 that the top surfaces of improved soil have a round, dome-shaped external appearance. It was also confirmed that the circular, stiff surfaces of improved soil continue laterally at least $1 \mathrm{~m}$ down below the excavated ground surface. It is therefore very likely that the circular columns of improved soil were produced at all the locations numbers 1-4. Schematic illustrations of the top surfaces of the largest column of improved soil at number 4 are also shown in Figure 9.

In what follows, the filling ratio $\alpha$ is estimated as follows. The relative density $D_{\mathrm{r}}$ was estimated as shown in Figures 5 and 6. The void ratio $e$ can then be calculated using the values of $e_{\max }=1.12$ and $e_{\min }=0.67$ of this sand deposit. Since the diameter of the improved soil column at number 1 is $\sim 1.5 \mathrm{~m}$

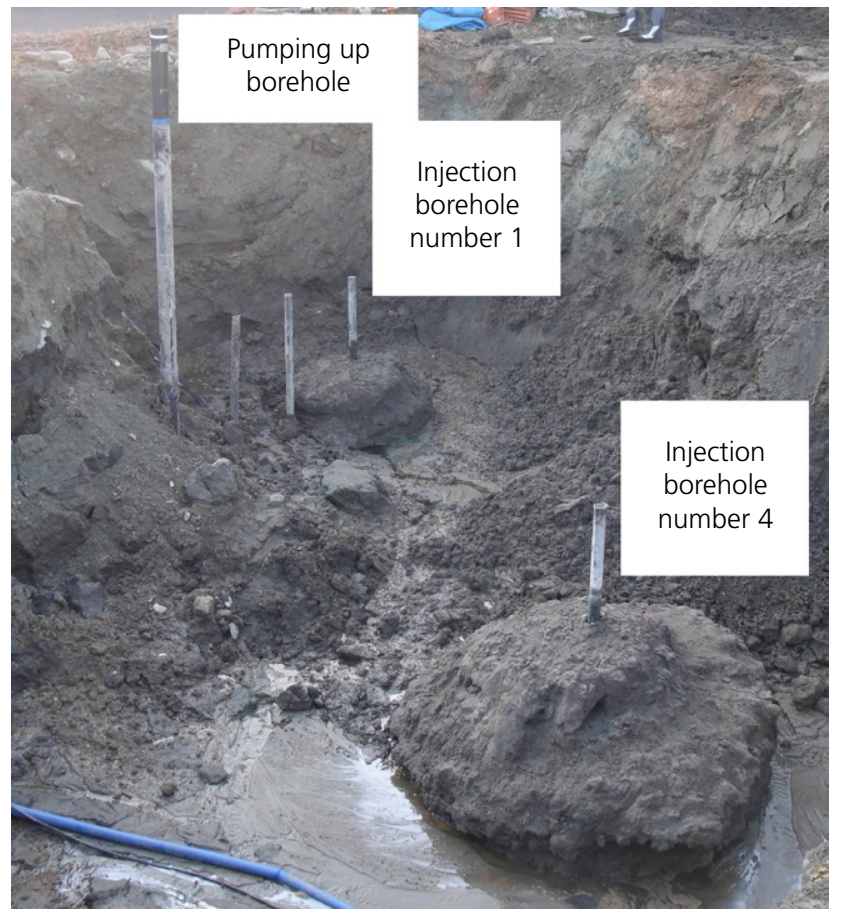

Figure 7. Confirmation of improved columns by means of excavation at injection boreholes numbers 1 and 4 and its height can be approximately assumed as $2.5 \mathrm{~m}$, the volume $V$ of the improved soil column at number 1 can be estimated accordingly. It therefore becomes possible to estimate the overall filling ratio $\alpha$, as follows

5. $\alpha=\frac{Q}{V n}$

where $Q$ is the volume of cement solutions infiltrated, and $n$ is the porosity, defined as $n=e /(1+e)$. In the present study, the

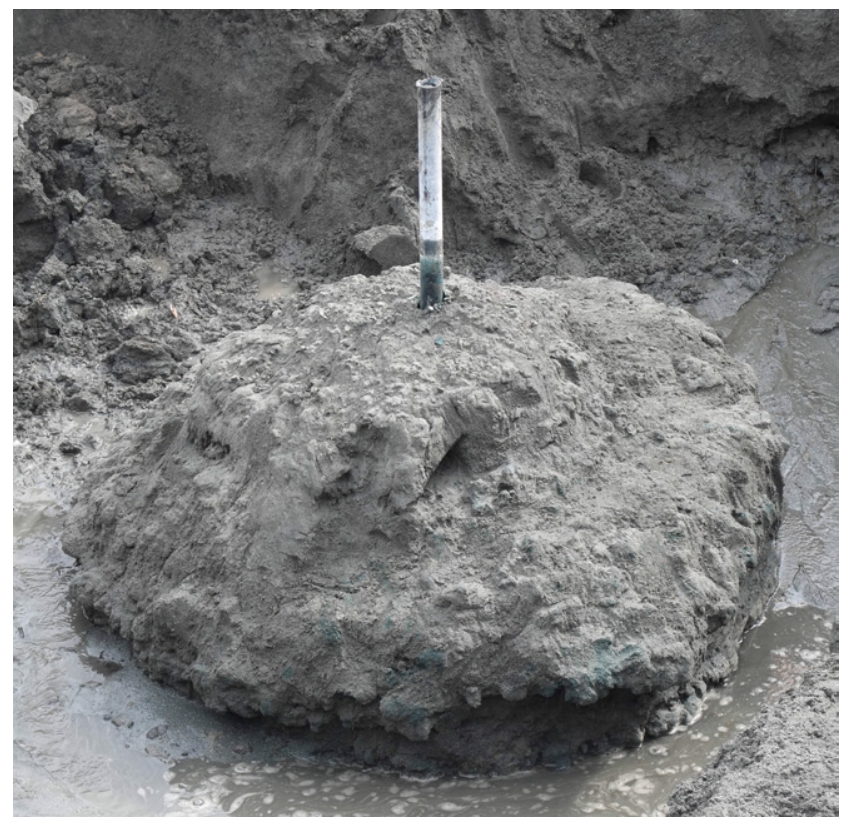

Figure 8. Close-up view of an improved column at injection borehole number 4

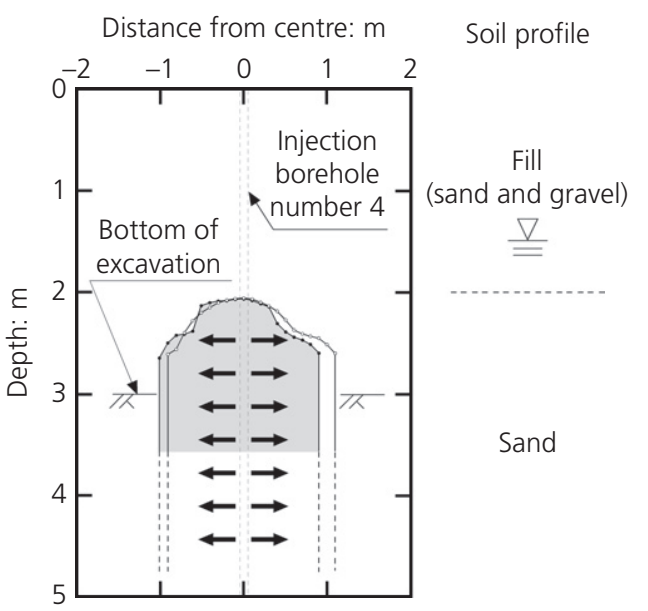

Figure 9. Surface contours of an improved column at injection borehole number 4 


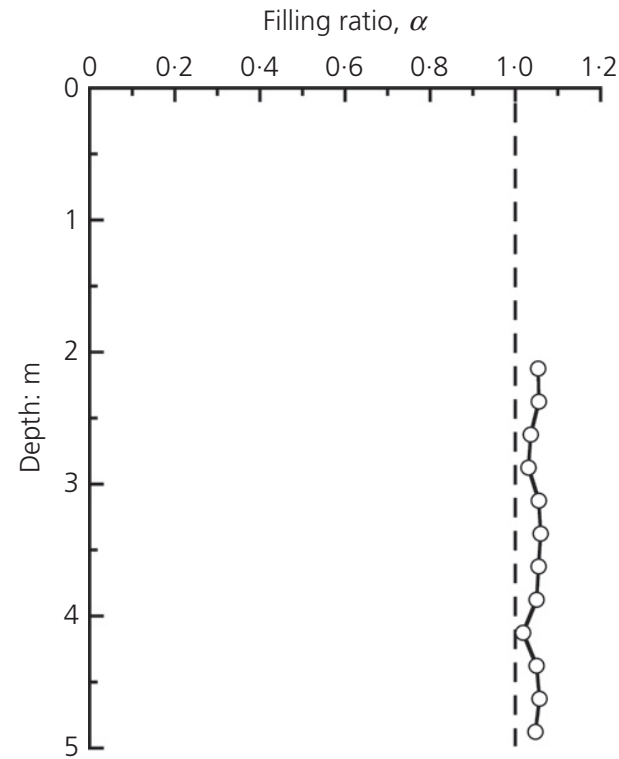

Figure 10. Estimated filling ratios $\alpha$ achieved at injection borehole number 1

values of $Q$ and $V$ are uniquely given for each column of improved soil at numbers $1-4$. The values of $n$, however, are estimated and distributed against depth. It is therefore possible to calculate the values of the filling ratio $\alpha$ by taking each value of $n$ distributed according to depth. Figure 10 shows the distribution of the values of the filling ratio $\alpha$ thus obtained at injection borehole number 1 . The filling ratio $\alpha$ is found to stay around 1 .

The ratio of mass of water to cement $(w / c)_{\text {is }}$ of the overall improved soil is estimated as follows. When the volumes (masses) of water and cement particles contained within a volume of soil designated for improvement, immediately after the injection of cement solutions, are defined as $V_{\mathrm{w}}$ and $V_{\mathrm{c}}$ ( $M_{\mathrm{w}}$ and $M_{\mathrm{c}}$ ), and the volumes (masses) of water and cement particles included in the cement solutions permeated into the improved soil are defined as $V_{\mathrm{w}}^{\prime}$ and $V_{\mathrm{c}}\left(M_{\mathrm{w}}^{\prime}\right.$ and $\left.M_{\mathrm{c}}\right)$, the following equations hold

6.

$$
V_{\mathrm{w}}+V_{\mathrm{c}}=V n, \quad V_{\mathrm{w}}^{\prime}+V_{\mathrm{c}}=Q,
$$

$$
\frac{M_{\mathrm{w}}^{\prime}}{M_{\mathrm{c}}}=\frac{V_{\mathrm{w}}^{\prime} \rho_{\mathrm{w}}}{V_{\mathrm{c}} \rho_{\mathrm{c}}}=(w / c)_{\mathrm{cs}}
$$

where $\rho_{\mathrm{c}}$ and $\rho_{\mathrm{w}}$ are the densities of cement particles and water, and $(w / c)_{\mathrm{cs}}$ is the ratio of mass of water to cement particles of the original cement solutions. The ratio of mass of water to cement particles $(w / c)_{\text {is }}$ of the overall improved soil can then be calculated as follows from Equation 6

7. $(w / c)_{\mathrm{is}}=\frac{M_{\mathrm{w}}}{M_{\mathrm{c}}}=\frac{V_{\mathrm{w}} \rho_{\mathrm{w}}}{V_{\mathrm{c}} \rho_{\mathrm{c}}}=\frac{V n}{Q}\left[(w / c)_{\mathrm{cs}}+\frac{\rho_{\mathrm{w}}}{\rho_{\mathrm{c}}}\right]-\frac{\rho_{\mathrm{w}}}{\rho_{\mathrm{c}}}$

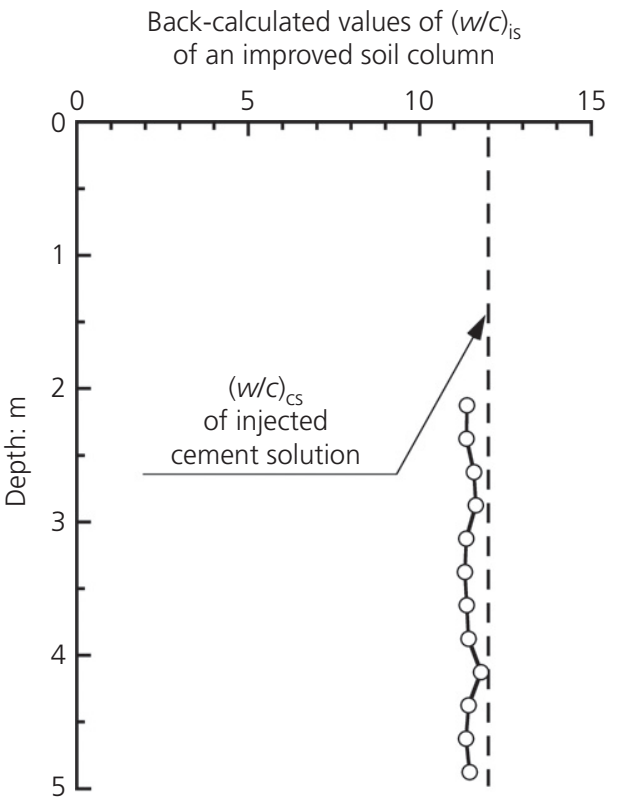

Figure 11. Back-calculated values of $(w / c)_{\text {is }}$ of an improved column at injection borehole number 1

Figure 11 shows the distribution of the values of $(w / c)_{\text {is }}$ thus obtained at the injection borehole number 1 . It is interesting to note that the ratio of mass of water to cement particles $(w / c)_{\text {is }}$ of the overall improved soil almost coincides with that of the original cement solutions $(w / c)_{\text {cs. }}$. The same observations can be found in Figures 12 and 13, which show the values of $\alpha$ and $(w / c)_{\text {is }}$ calculated at the injection borehole number 4 . It should be noticed here that manipulating Equations 5-7 yields the

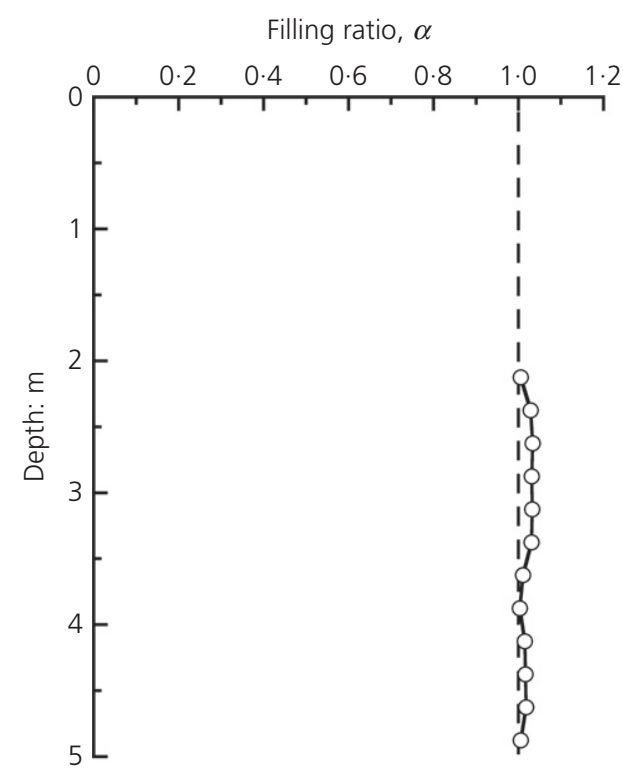

Figure 12. Estimated filling ratios $\alpha$ achieved at injection borehole number 4 


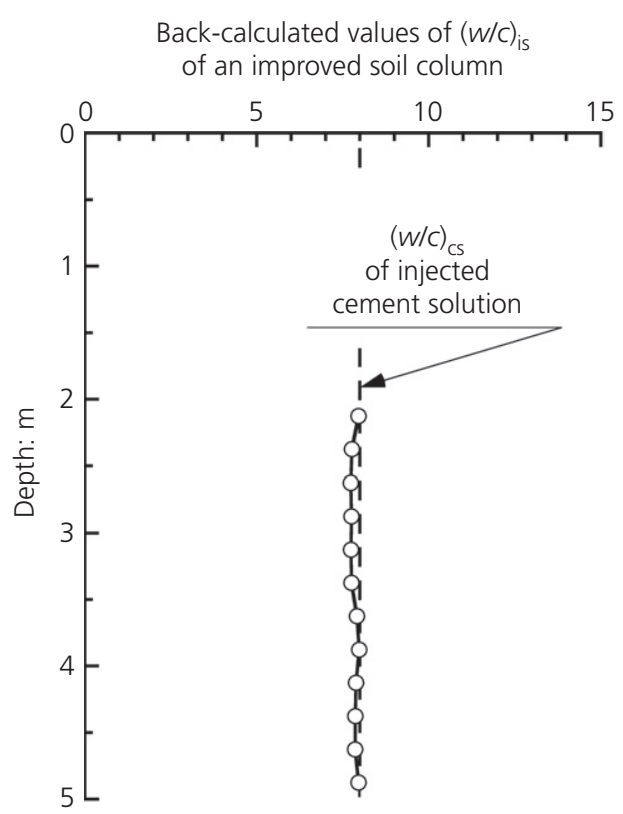

Figure 13. Back-calculated values of $(w / c)$ is of an improved column at injection borehole number 4

relation between $\alpha$ and $(w / c)_{\text {is }}$ as follows

8. $\alpha=\frac{\rho_{\mathrm{w}} / \rho_{\mathrm{c}}+(w / c)_{\mathrm{cs}}}{\rho_{\mathrm{w}} / \rho_{\mathrm{c}}+(w / c)_{\mathrm{is}}}$

It can therefore easily be found that the filling ratio $\alpha$ is equal to 1 when $(w / c)_{\text {is }}$ is equal to $(w / c)_{\mathrm{cs}}$. Although these two parameters $\alpha$ and $(w / c)_{\text {is }}$ are related to each other, the importance of introducing the definition of $(w / c)_{\text {is }}$ separately from the filling ratio $\alpha$ is demonstrated as follows. It is reasonable to assume that there should be some threshold value of $(w / c)_{\mathrm{o}}$, where solidification of a soil deposit would take place due to the presence of cement solutions; the authors assume this to exist in the range of $(w / c)_{\mathrm{o}}=8-12$, based on the results of laboratory tests conducted, as shown in Figure 14. In the laboratory tests, two soil samples of Urayasu sand were used, which were retrieved as sand boil materials from the city of Urayasu, where extensive soil liquefaction was observed during the Great East Japan Earthquake in 2011. These two soil samples have different values of fines content $<0.075 \mathrm{~mm}$ in particle diameter of $F_{\mathrm{c}}=0 \%$ and $40 \%$, with the mean particle diameters of $D_{50}=0.12$ and $0.08 \mathrm{~mm}$. The cement powders were then mixed with wet soil samples to achieve particular values of $w / c$. Cylindrical specimens with a relative density of $D_{\mathrm{r}}=80 \%$ were produced by the method of wet tamping and then saturated. After a curing period of 1 month, laboratory unconfined compression tests were conducted on the specimens that had solidified, whereas saturated, isotropically consolidated, undrained, cyclic triaxial tests were conducted on the

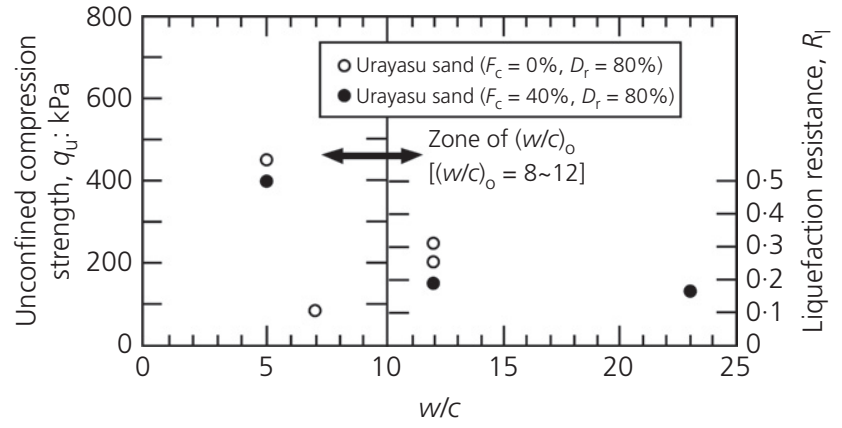

Figure 14. Presence of $(W / c)_{\circ}$ (Urayasu sand, $F_{c}=0 \%$ and $40 \%$, $\left.D_{\mathrm{r}}=80 \%\right)$

specimens that had not solidified. In Figure 14, the data of unconfined compression strength $q_{\mathrm{u}}$ and liquefaction resistance $R_{1}$ are plotted against $w / c$. It is found that there appears to be a threshold value of $(w / c)_{0}$, below which soil specimens would solidify. Acknowledging the presence of $(w / c)_{\mathrm{o}},(w / c)_{\text {is }}$ needs to take a value lower than $(w / c)_{0}$, in order for a soil deposit to solidify. Combining this assumption and Equation 8 leads to the following equation

9. $\quad \alpha \geq \frac{\rho_{\mathrm{w}} / \rho_{\mathrm{c}}+(w / c)_{\mathrm{cs}}}{\rho_{\mathrm{w}} / \rho_{\mathrm{c}}+(w / c)_{\mathrm{o}}}$

It is also necessary to bear in mind in Equation 9 that the choice of a value of $(w / c)_{\text {cs }}$ apparently affects the permeability of cement solutions through fine-grained soils. With this in mind and assuming that the threshold value of $(w / c)_{\mathrm{o}}$ is equal to 12 , in the case where a less dense, although more permeable cement solution of $(w / c)_{\mathrm{cs}}$ as high as 16 is used, the filling ratio $\alpha$ needs to be larger than about 1.32 according to Equation 9, which would make the volume of improved soil smaller at a given value of $Q$ according to Equation 5. In contrast, when a denser, although less permeable cement solution of $(w / c)_{\mathrm{cs}}$ as low as 8 is used, the filling ratio $\alpha$ needs to be larger than about $0 \cdot 68$. This could imply that it would be possible to make the volume of improved soil larger in principle, although the cement solution itself is less permeable, which would make it difficult to achieve a larger volume of improved soil, conversely.

The numerical evidence in Figures 10-13 might indicate that the cement solutions introduced from injection boreholes would have permeated through voids of a saturated sand deposit without changing their concentration, and the radial distance that the cement solutions travelled would have determined the radius of a column of improved soil. This would in turn imply that, as far as clean sand deposits are concerned and where the density of a sand deposit is given, the radius of an improved soil column can be determined solely from the 
volume of cement solutions infiltrated into the sand deposit, by assuming a filling ratio $\alpha$ of almost unity.

\section{Conclusions}

The application of permeation grouting of ultra-microfine cement was demonstrated in field tests, and proved to be capable of creating columns of improved soil of an affordable size in sand deposits, which would be expected to contribute to improving ground conditions as a countermeasure against soil liquefaction. In the present study, columns of improved soil of diameter $1.5-2 \mathrm{~m}$ and $2.5 \mathrm{~m}$ high were produced in relatively clean sand deposits of depth $3 \mathrm{~m}$, by introducing cement solutions with concentrations of $(w / c)_{\mathrm{cs}}=8$ and 12 through boreholes set up along the entire depths of the sand deposits. It was also found that, for clean sand deposits, the filling ratio $\alpha$ can be assumed as almost unity. It is therefore adequate to presume that the radius of a column of improved soil can be estimated solely from the volume of cement solutions injected into sand deposits.

\section{Acknowledgements}

The present study is funded by the Japanese Ministry of Land, Infrastructure and Transport. The authors acknowledge the kind support and advice from Professors S. Yasuda and M. Nishigaki. The test site for the field tests was offered by YBM Co. Ltd, Japan. The laboratory tests shown in Figure 14 were conducted with a help of S. Hagiwara, a past student of Tokyo University of Science.

\section{REFERENCES}

Granata R, Vanni D and Mauro M (2015) New experience in ground treatment by permeation grouting. Proceedings of the Institution of Civil Engineers - Ground Improvement 168(2): 122-129, http://dx.doi.org/10.1680/grim.13.00026.

Hashimoto K, Nishihara S, Oji S et al. (2015) Developing geotechnology for permeation grouting of ultra microfine cement to locally countermeasure against soil liquefaction. Proceedings of the 6th International Conference on Earthquake Geotechnical Engineering, Christchurch, New Zealand, in press.

JGS (Japanese Geotechnical Society) (2000) Testing Methods and Interpretations of Geotechnical Laboratory Experiments. Japanese Geotechnical Society, Tokyo, Japan (in Japanese).

Kanazawa T (2012) Applications of Ultra Microfine Cement to Geotechnical Engineering. $\mathrm{PhD}$ thesis, Okayama University, Okayama, Japan (in Japanese).

Lirer S, Flora A, Evangelista A et al. (2006) Permeation grouting of a fine-grained pyroclastic soil. Proceedings of the Institution of Civil Engineers - Ground Improvement 10(4): 135-145, http://dx.doi.org/10.1680/grim.2006.10.4.135.

Markou IN and Droudakis AI (2013) Shear strength of microfine cement grouted sands. Proceedings of the Institution of Civil Engineers - Ground Improvement 166(3): 177-186, http://dx.doi.org/10.1680/grim.12.00016.
Mitrani H and Madabhushi SPG (2010) Cementation liquefaction remediation for existing buildings. Proceedings of the Institution of Civil Engineers - Ground Improvement 163(2): 81-94, http://dx.doi.org/10.1680/grim. 2010.163.2.81

Siddharthan RV and Porbaha A (2008a) Seismic response evaluation of sites improved by deep mixing, part I: proposed approach. Proceedings of the Institution of Civil Engineers - Ground Improvement 161(3): 153-162, http:// dx.doi.org/10.1680/grim.2008.161.3.153.

Siddharthan RV and Porbaha A (2008b) Seismic response evaluation of sites improved by deep mixing, part 2 : verification. Proceedings of the Institution of Civil Engineers - Ground Improvement 161(3): 163-169, http:// dx.doi.org/10.1680/grim.2008.161.3.163.

Tsukamoto Y, Ishihara K and Sawada S (2004) Correlation between penetration resistance of Swedish weight sounding tests and SPT blow counts in sandy soils. Soils and Foundations 44(3): 13-24.

Tsukamoto Y, Ishihara K, Umeda K and Enomoto T (2006) Cyclic resistance of clean sand improved by silicate-based permeation grouting. Soils and Foundations 46(2): 233-245.

Tsukamoto Y, Ishihara K, Umeda K et al. (2007) Small strain properties and cyclic resistance of clean sand improved by silicate-based permeation grouting. Soil Stress-Strain Behavior: Measurement, Modeling and Analysis: A Collection of Papers of the Geotechnical Symposium in Rome 2006, Rome, Italy (Ling HI, Callisto L, Leshchinsky $\mathrm{D}$ and Koseki $\mathrm{J}$ (eds)). Springer, pp. 503-511.

Tsukamoto Y, Hyodo T and Fuki N (2015) Some recent applications of Swedish weight sounding tests to earthquake reconnaissance investigations. Proceedings of 6th International Conference on Earthquake Geotechnical Engineering, Christchurch, New Zealand, in press.

Tunç demir F and Ergun U (2009) Fracture grouting of sand by microfine cement grouts. Proceedings of the Institution of Civil Engineers - Ground Improvement 162(2): 93-101, http://dx.doi.org/10.1680/grim.2009.162.2.93.

\section{WHAT DO YOU THINK?}

To discuss this paper, please email up to 500 words to the editor at journals@ice.org.uk. Your contribution will be forwarded to the author(s) for a reply and, if considered appropriate by the editorial panel, will be published as discussion in a future issue of the journal.

Proceedings journals rely entirely on contributions sent in by civil engineering professionals, academics and students. Papers should be 2000-5000 words long (briefing papers should be 1000-2000 words long), with adequate illustrations and references. You can submit your paper online via www.icevirtuallibrary.com/content/journals, where you will also find detailed author guidelines. 